\title{
\$ms
}

\section{A natural fungal infection of a sylvatic cockroach with Metarhizium blattodeae sp. nov., a member of the M. flavoviride species complex}

\author{
Cristian MONTALVA ${ }^{a}$, Karin COLLIER ${ }^{b}$, Luiz Fernando Nunes ROCHA $^{a, c}$, \\ Peter Ward INGLIS ${ }^{d}$, Rogério Biaggioni LOPES ${ }^{d}$, Christian LUZ ${ }^{a}$, \\ Richard A. HUMBER ${ }^{e, *}$ \\ anstituto de Patologia Tropical e Saúde Pública (IPTSP), Universidade Federal de Goiás (UFG), Goiânia 74605-050, \\ Goiás, Brazil \\ ${ }^{\mathrm{b}}$ Centro Universitário de Gurupí (UnirG), Gurupí 77425-500, Tocantins, Brazil \\ 'Instituto Federal de Educação, Ciência e Tecnologia de Goiás (IFG), Aparecida de Goiânia 74968-755, Goiás, Brazil \\ dEmbrapa Recursos Genéticos e Biotecnologia, Brasília 70770-917, Distrito Federal, Brazil \\ eUSDA-ARS Emerging Pests and Pathogens Research Unit, Robert W. Holley Center for Agriculture and Health, \\ Ithaca, NY, 14853-2901, USA
}

\section{A R T I C L E I N F O}

\section{Article history:}

Received 16 December 2015

Received in revised form

7 March 2016

Accepted 8 March 2016

Available online 16 March 2016

Corresponding Editor:

Nicholas P Money

Keywords:

Blattodea

Brazil

Clavicipitaceae

Entomopathogenic fungus

Goiás

\begin{abstract}
A B S T R A C T
A wild, forest-dwelling cockroach from the subfamily Ectobiidae (order Blattodea) in a nature reserve in Cavalcante, in the state of Goiás, Brazil, was found to be infected by a new, genetically distinct species in the Metarhizium flavoviride species complex that we describe here as Metarhizium blattodeae. The status of this fungus as a new species is supported by both multigenic sequence comparisons and protein profiles generated by MALDI-TOF (matrix-assisted laser desorption/ionization time-of-flight) mass spectrometry. This is one of the first reports of a naturally occurring fungal pathogen affecting any sylvatic (forest-dwelling) cockroach from any part of the world. M. blattodeae caused up to $96 \%$ mortality of Periplaneta americana nymphs (a serious peridomestic cockroach species) after $10 \mathrm{~d}$. Published by Elsevier Ltd on behalf of The British Mycological Society.
\end{abstract}

\section{Introduction}

Hypocrealean entomopathogenic fungi have long been studied as candidates for the microbial control of synanthropic cockroach pests. The cosmopolitan German and American cockroaches, Blattella germanica and Periplaneta americana (Blattodea), respectively, are among the most troublesome of household insect pests and are well known for both their

\footnotetext{
* Corresponding author. Emerging Pests and Pathogens Research, Robert W. Holley Center for Agriculture and Health, 538 Tower Road, Ithaca, NY, 14853-2901, USA. Tel.: +1 607255 1276; fax: +1 6072551132.

E-mail addresses: montalva.cristian@gmail.com (C. Montalva), karincollier@gmail.com (K. Collier), luizfnr@hotmail.com (L. F. N. Rocha), peterwinglis@gmail.com (P.W. Inglis), rogerio.lopes@embrapa.br (R. B. Lopes),wchrisluz@hotmail.com (C. Luz), richard.humber@ars.usda.gov, richard.humber@usda.gov, rah3@cornell.edu (R. A. Humber). 
hardiness and their ability to evade diverse control measures. Fungal activity against these insects has been shown with the important and widely used fungal biocontrol agents Beauveria bassiana and Metarhizium anisopliae (Mohan et al. 1999; Quesada-Moraga et al. 2004; Abedi \& Dayer 2005; Lopes \& Alves 2011; Hubner-Campos et al. 2013; Gutierrez et al. 2015). Knowledge about the potential of these fungi for cockroach control is based mainly on assays done under laboratory conditions with fungal strains originating from other host insects or substrates. Studies on cockroaches as target hosts have often emphasized the combined effects of fungus and synthetic insecticides (Kaakeh et al. 1996, 1997; Zurek et al. 2002). One commercialized mycoinsecticide based on M. anisopliae was registered with the US Environmental Protection Agency (Registration \#70644-8) for cockroach control (Faria \& Wraight 2007), but this registration has since been cancelled, and the manufacturer, EcoScience Corporation, is no longer in business. In Guatemala, however, a Metarhizium-based product (Zero QK-S 0,4 DP) has been sold by Agricola El Sol for use against domestic cockroach pests for many years.

More than 4000 cockroach species are known worldwide, but most have no importance as pests and mostly live far from human habitations (Bell et al. 2007; Beccaloni 2014). There are surprisingly few reports of natural fatal infections of any cockroach species, synanthropic or not, caused by any fungus that is clearly pathogenic for these insects, and these reports generally suggest that only very few cockroach individuals were negatively affected by these fungi. Although Roth \& Willis (1960) compiled a surprisingly long list of fungi and yeasts from cockroaches, most of these fungi are primarily saprobic or facultative pathogens, and many were reported only from gut contents or feces. The cockroach fungi noted by Roth \& Willis (1960) that cause diseases of insects include ectoparasitic ascomycetes (Herpomyces species: Laboulbeniales) and the cordycipitoid fungi now classified as Ophiocordyceps amazonica and Ophiocordyceps blattae (Hypocreales: Ophiocordycipitaceae), as well as a few poorly supported reports of Metarhizium.

Archbold et al. (1987) and Appel et al. (1987) studied an entomopathogenic yeast affecting the German cockroach, B. germanica. One of the authors (RAH) is aware of an unpublished finding in the early 1980's of an entomophthoralean fungus, probably Batkoa species based on the globose shape of the conidia, affecting cockroaches in a grain field near the Rothamsted Experimental Station in the United Kingdom. Hymenostilbe ventricosa was described from forest-dwelling cockroach nymphs in Thailand (Hywel-Jones 1995), and Cummings (2009) reported finding B. bassiana affecting single cockroaches at two different locations within New Zealand.

The cockroach from which this new fungus was isolated was collected as part of routine survey of vegetation and soil surfaces adjacent to aquatic sites where the primary intention of the field work was to find fungal pathogens of mosquitoes and other dipteran vectors of serious human and animal diseases. These vegetation surveys were undertaken to help to expand the comparatively poor understanding of the biota of Brazilian fungal entomopathogens (Sosa-Gómez et al. 2010). The scarcity of information about such fungi, especially in nonagricultural sites, is primarily a result of the lack of collecting efforts to find such fungi.
The present study reports a natural infection by Metarhizium blattodeae sp. nov. affecting a sylvatic cockroach species collected in Central Brazil. The status of this new species is supported by both gene sequence and mass spectrometric data about the proteins on its conidial surfaces, and we characterize the morphology and confirm the pathogenicity of this new fungus against P. americana nymphs under laboratory conditions.

\section{Material and methods}

\section{Field location, collecting and initial processing of material}

The survey for entomopathogenic fungi in which this new fungus was found was done during the rainy season (February 2015) in a tropical secondary gallery forest in the privately owned and operated Bacupari Reserve, close to the city of Cavalcante in northern Goiás state, Central Brazil. Leaves in the vegetation up to $2 \mathrm{~m}$ high, as well as plant remains on the soil, were checked for mycotized arthropod cadavers. Material with dead specimens was carefully removed, transferred to paper bags and placed in a polystyrene cooler at $20^{\circ} \mathrm{C}$ (Benjamin et al. 2004) for later examination and processing in a field laboratory.

Dead arthropods and their fungal pathogens were examined microscopically for their taxonomically significant morphological characteristics, and conidia were subsequently transferred to quarter-strength Sabouraud dextrose agar + yeast extract (SDAY/4: $2.5 \mathrm{~g} \mathrm{~L}^{-1}$ peptone, $10 \mathrm{~g} \mathrm{~L}^{-1}$ dextrose, $2.5 \mathrm{~g} \mathrm{~L}^{-1}$ yeast extract, $20 \mathrm{~g} \mathrm{~L}^{-1}$ agar) amended with chloramphenicol $(0.05 \%)$ in $60 \times 15 \mathrm{~mm}$ Petri dishes. Dishes were sealed with parafilm and incubated at $25 \pm 3{ }^{\circ} \mathrm{C}$ and natural photophase. The development of fungi and of any contaminants was checked daily, and contaminants were removed or clean transfers of uncontaminated fungal growth from the presumptive pathogen were made to fresh medium. Once a pure culture was established, all further transfers were onto SDAY/4 without additional antibiotics.

The fungus reported here was prepared for long-term preservation in the IPTSP Laboratory of Invertebrate Pathology as IP 414 following protocols from Humber (2012b), and was also co-deposited in the USDA Collection of Entomopathogenic Fungi (Ithaca, NY) as ARSEF 12850.

\section{Morphological evaluations}

An infected cockroach was identified morphologically based on keys in Costa Lima (1938). Conidial inoculum from this fungus was grown at $25 \pm 1{ }^{\circ} \mathrm{C}, 75 \pm 10 \%$ relative humidity ( $\mathrm{RH}$ ) and a $12 \mathrm{~h}$ photophase on Sabouraud dextrose agar for $14 \mathrm{~d}$ (Bischoff et al. 2009). The fungus was investigated based on morphological characteristics, and semi-permanent slide mounts were prepared in lactophenol-cotton blue according to Humber (2012a). Fungal microstructures were examined by brightfield or phase contrast microscopy (Leica DMLS 020518.500), measured microscopically (Nova 180i-T; Toupview) and documented with a digital camera (UCMOS01300KPA). Photomontages of multiple focal planes for the conidia and conidiophores were prepared using Helicon Focus Pro software (www.heliconsoft.com). Measurements were based on 
50 objects per microstructure from which we calculated mean values, standard error of the mean $( \pm \mathrm{SEM})$, and a range with the maximum and minimum values.

\section{In vivo characterization}

The pathogenicity of the fungus was tested in laboratoryreared first up to fourth instar Periplaneta americana nymphs (Hubner-Campos et al. 2013). Ten nymphs for each repetition, and the same number for all controls, were sedated with carbon dioxide and then treated with an undefined quantity of conidia on the thorax and abdomen of each nymph by a very brief direct contact with the sporulated culture. Viability of conidia was checked as reported by Sousa et al. (2013). Nymphs were then incubated in a Petri dish $(90 \times 18 \mathrm{~mm})$ at $25 \pm 1{ }^{\circ} \mathrm{C}, \mathrm{RH}$ close to saturation (>98\%) and a $12 \mathrm{~h}$ photoperiod. Every three days, the infected nymphs were provided with new ground, dry cat food (0.5 g) (Whiskas ${ }^{\circledR}$, Mars Brazil, Guararema, SP, Brazil) and water through moistened cotton wool $(0.1 \mathrm{ml})$ arranged in separate small aluminium containers. Control nymphs were not treated with conidia and were held as mentioned. Mortality was monitored daily, and dead nymphs were transferred to sterile filter paper in new Petri dishes and incubated in a humid chamber at $25 \pm 1{ }^{\circ} \mathrm{C}$. Development of mycelium and conidia on cadavers was checked daily for up to $15 \mathrm{~d}$, and the fungus was examined morphologically with a stereomicroscope and compared with the fungus inoculated previously.

\section{Molecular characterization}

The fungal isolate was grown in liquid SDY/4 for $7 \mathrm{~d}$ in a shaker at $150 \mathrm{rpm}$ and $25 \pm 1{ }^{\circ} \mathrm{C}$. DNA was extracted from mycelium using the DNeasy Plant Mini Kit (Qiagen, Valencia, CA, USA). Partial sequences of four genes were amplified by PCR including: beta tubulin (BTUB) using the primers BT1F and BT1R (Bischoff et al. 2009); RNA polymerase II largest subunit (RPB1a) with RPB1C and RPB1Af (Stiller \& Hall 1997); RNA polymerase II second largest subunit (RPB2a) with fRPB2-5F and RPB2-7cR (Liu et al. 1999) and translation elongation factor 1 alpha (TEF) with primers 983F and 2218R (Rehner \& Buckley 2005). The internal transcribed spacer (ITS) regions ITS1 and ITS2 as well as the central 5.8S rDNA were also amplified using the primers ITS1 and ITS4 (White et al. 1990). The PCR products were checked using agarose gel electrophoresis, and bands were then purified. Sequencing of both strands of the PCR products was accomplished with the Applied Biosystems Big Dye v.3.1 kit, using the same primers described above and an ABI 3500 automatic sequencer.

Contigs of IP 414 sequence data were assembled using Chromas Pro (V. 1.5, Technelysium Pty Ltd). Reference sequences used in two recent taxonomic re-evaluations of Metarhizium (Bischoff et al. 2009; Kepler et al. 2014) and others sequences were obtained from GenBank and are listed in Table 1. Individual gene regions were aligned using MAFFT v. 7 with the G-INS-i option (Katoh \& Standley 2013), and the multiple alignments were trimmed to the length of the IP 414 sequences. A concatenated matrix comprising partial BTUB, RPB1a, RPB2a and TEF sequences was assembled in
Sequence Matrix v. 1.7.8 (Meier et al. 2006), totalling 3205 aligned characters.

A phylogenetic hypothesis based on the concatenated matrix was obtained using the Bayesian Markov Chain Monte Carlo method as implemented in MrBayes 3.2.5 (Ronquist et al. 2012). Default program settings were used, except that reversible-jump MCMC (Huelsenbeck et al. 2004) was implemented to optimize the analysis within the GTR model family (nst $=$ mixed rates $=$ invgamma). Model parameters varied freely over the four component data partitions, and the analysis run for five million generations, with the first $25 \%$ of trees discarded as burn-in. This run-time was sufficient to allow the convergence diagnostic, the standard deviation of split frequencies, to fall to 0.0002365 . The analysis was repeated to ensure reproducibility of the resultant majority rule phylogram.

To supplement the results of the combined gene analysis, rRNA-ITS sequences from Metarhizium species close to IP 414 , including as many of the same isolates as in the previous analysis as currently available, were also obtained from GenBank. The ITS sequences were aligned as above and trimmed, producing a matrix of 621 aligned characters. A phylogenetic hypothesis was again calculated in MrBayes 3.2.5 as above, but with two million generations being sufficient to produce a standard deviation of split frequencies of 0.006008 .

\section{Protein analysis by Matrix-Assisted Laser Desorption/ Ionization Time-of-Flight mass spectrometry (MALDI-TOF MS)}

Conidia were collected from 10 to 12 -d-old cultures on potato dextrose agar (PDA) and transferred to 2-mL plastic tubes containing $1 \mathrm{~mL}$ of ethanol (75\%). The suspension was agitated manually for $30 \mathrm{~s}$ and then centrifuged at $16100 \times \mathrm{g}$ for $2 \mathrm{~min}$. The supernatant was discarded, and the pellets were air-dried at room temperature for $15 \mathrm{~min}$. Protein extraction and spectral analysis were performed as described by Lopes et al. (2014a). Briefly, conidial pellets were acid digested in $50 \mu \mathrm{L}$ formic acid $(70 \%)$ and $50 \mu \mathrm{L}$ of acetonitrile (100\%) before centrifugation (16100 $\times \mathrm{g}$ for $2 \mathrm{~min})$. The supernatant was diluted in deionized water (1:10 v/v), directly spotted ( $1 \mu \mathrm{L}$ droplet) onto a steel target plate, and allowed to air-dry for $15 \mathrm{~min}$. A 1- $\mu \mathrm{L}$ droplet of $\alpha$-cyano-4-hydroxycinnamic acid matrix solution was applied to the dried sample and air-dried for $15 \mathrm{~min}$. Analyses were performed on a MicroFlex Speed ${ }^{\mathrm{TM}}$ MALDI-TOF mass spectrometer (Bruker Daltonick GmbH, Bremen, Germany). Each spectrum was obtained after an average of 240 laser shots, and the signals were automatically collected at a mass range between 2000 and $20000 \mathrm{~m} / \mathrm{z}$. Six independent samples were prepared for the IP 414 isolate. The collected spectra were analysed with the Biotyper software algorithm (version 3.1) to match the number and intensity of peaks in the raw spectra with those in the Metarhizium reference main spectrum profile (MSP) database. Spectra matching results were expressed as log score values in a 0-3 scale. The IP 414 consensus spectrum was incorporated into the MSP database and submitted to cluster analyses (MSP Dendrogram Creation Standard Method, version 1.4), comparing with spectrum profiles from different species within the genus Metarhizium. 
Table 1 - Reference sequences used for phylogenetic analysis; genes and locus with no deposited sequences are left blank.

\begin{tabular}{|c|c|c|c|c|c|c|c|c|}
\hline \multirow[t]{2}{*}{ Species } & \multirow[t]{2}{*}{ Strain ${ }^{a}$} & \multirow[t]{2}{*}{ Host/substrate } & \multirow[t]{2}{*}{ Location } & \multicolumn{5}{|c|}{ GenBank accession number } \\
\hline & & & & RPB1a & RPB2a & TEF & BTUB & ITS \\
\hline Metapochonia bulbillosa & CBS 247.68 & wheat field soil & Germany & KJ398599 & KJ398695 & KJ398788 & KJ398556 & \\
\hline Metapochonia microbactrospora & CBS $1014.33^{b}$ & bdelloid rotifers & Japan & KJ398605 & KJ398701 & KJ398794 & KJ398562 & \\
\hline Metapochonia rubescens & CBS 1104.36 & soil & Netherlands & KJ398606 & KJ398702 & KJ398795 & KJ398563 & \\
\hline Metapochonia suchlasporia var. catenata & CBS $248.83^{b}$ & nematode eggs & Sweden & KJ398600 & KJ398696 & KJ398789 & KJ398557 & \\
\hline Metapochonia suchlasporia var. catenata & CBS 814.83 & nematode eggs & Sweden & KJ398604 & KJ398700 & KJ398793 & KJ398561 & \\
\hline Metapochonia suchlasporia var. suchlasporia & CBS $251.83^{b}$ & nematode eggs & Sweden & KJ398601 & KJ398697 & KJ398790 & KJ398558 & \\
\hline Metarhizium acridum & ARSEF 324 & Orthoptera & Australia & EU248896 & EU248924 & EU248844 & EU248812 & HM055449 \\
\hline Metarhizium acridum & ARSEF $7486^{\mathrm{b}}$ & Orthoptera & Niger & EU248897 & EU248925 & EU248845 & EU248813 & \\
\hline Metarhizium album & ARSEF 1942 & Hemiptera & Philippines & KJ398611 & KJ398709 & KJ398802 & KJ398572 & HM055452 \\
\hline Metarhizium album & ARSEF 2082 & Hemiptera & Indonesia & KJ398617 & KJ398715 & DQ522352 & KJ398579 & \\
\hline Metarhizium album & ARSEF 2179 & Hemiptera & Philippines & KJ398618 & KJ398716 & KJ398807 & KJ398580 & \\
\hline Metarhizium anisopliae & ARSEF 7450 & Coleoptera & Australia & & & & & HQ331464 \\
\hline Metarhizium anisopliae & ARSEF $7487^{\mathrm{b}}$ & Orthoptera & Ethiopia & DQ468355 & DQ468370 & DQ463996 & EU248822 & HQ331446 \\
\hline Metarhizium blattodeae & IP $414^{b}$ & Ectobiidae & Brazil & KU182918 & KU182916 & KU182917 & KU182914 & KU182915 \\
\hline Metarhizium brasiliense & ARSEF $2948^{b}$ & Hemiptera & Brazil & KJ398620 & KJ398718 & KJ398809 & KJ398582 & \\
\hline Metarhizium brunneum & ARSEF $2107^{b}$ & Coleoptera & USA & EU248907 & EU248935 & EU248855 & EU248826 & \\
\hline Metarhizium brunneum & ARSEF 4179 & soil & Australia & EU248906 & EU248934 & EU248854 & EU248825 & \\
\hline Metarhizium carneum & CBS $239.32^{\mathrm{b}}$ & dune sand & France & EF468894 & EF468938 & EF468789 & KJ398547 & \\
\hline Metarhizium cylindrosporum & ARSEF 6926 & Hemiptera & Taiwan & KJ398625 & KJ398723 & KJ398814 & KJ398587 & \\
\hline Metarhizium cylindrosporum & CBS $256.90^{\mathrm{b}}$ & Hemiptera & China & KJ398594 & KJ398691 & KJ398783 & KJ398543 & \\
\hline Metarhizium flavoviride & ARSEF 1184 & Otiorhynchus sulcatus & France & & & & & AY646383 \\
\hline Metarhizium flavoviride & ARSEF 2025 & soil & Germany & KJ398614 & KJ398712 & KJ398804 & KJ398575 & AF138269 \\
\hline Metarhizium flavoviride & ARSEF 4275 & soil & Australia & & & & & AY646398 \\
\hline Metarhizium flavoviride & CBS $218.56^{\mathrm{b}}$ & Coleoptera & Czech Republic & KJ398598 & KJ398694 & KJ398787 & KJ398555 & \\
\hline Metarhizium frigidum & ARSEF $4124^{b}$ & Coleoptera & Australia & DQ468361 & DQ468376 & DQ464002 & EU248828 & HM055448 \\
\hline Metarhizium frigidum & ARSEF 4343 & soil & Australia & & & & & FJ617324 \\
\hline Metarhizium frigidum & ARSEF 4561 & soil & Australia & & & & & FJ617345 \\
\hline Metarhizium frigidum & ARSEF 7445 & Isoptera & Australia & KJ398628 & KJ398727 & KJ398818 & KJ398590 & \\
\hline Metarhizium globosum & ARSEF 2596 & Lepidoptera & India & EU248898 & EU248926 & EU248846 & EU248814 & \\
\hline Metarhizium granulomatis & UAMH $11028^{b}$ & Chamaeleo calyptratus & Denmark & & KJ398688 & KJ398781 & KJ398540 & \\
\hline Metarhizium granulomatis & UAMH 11176 & Chamaeleo calyptratus & Denmark & KJ398593 & KJ398689 & KJ398782 & KJ398541 & \\
\hline Metarhizium guizhouense & ARSEF 6238 & Lepidoptera & China & EU248909 & EU248937 & EU248857 & EU248830 & \\
\hline Metarhizium guizhouense & CBS $258.90^{\mathrm{b}}$ & Lepidoptera & China & EU248914 & EU248942 & EU248862 & EU248834 & \\
\hline Metarhizium indigoticum & NBRC 100684 & Lepidoptera & Japan & KJ398595 & KJ398692 & KJ398784 & KJ398544 & \\
\hline Metarhizium khaoyaiense & BCC 12687 & Lepidoptera & Thailand & JN049888 & KJ398703 & KJ398796 & KJ398564 & \\
\hline Metarhizium khaoyaiense & BCC 14290 & Lepidoptera & Thailand & JN049889 & KJ398704 & KJ398797 & KJ398565 & \\
\hline Metarhizium koreanum & ARSEF $2038^{b}$ & Hemiptera & Korea & KJ398615 & KJ398713 & KJ398805 & KJ398577 & HM055431 \\
\hline Metarhizium koreanum & ARSEF 2039 & Hemiptera & Korea & KJ398616 & KJ398714 & KJ398806 & KJ398578 & \\
\hline Metarhizium lepidiotae & ARSEF 7412 & Coleoptera & Australia & EU248916 & EU248944 & EU248864 & EU248836 & \\
\hline Metarhizium lepidiotae & ARSEF $7488^{b}$ & Coleoptera & Australia & EU248917 & EU248945 & EU248865 & EU248837 & \\
\hline Metarhizium majus & ARSEF $1914^{\mathrm{b}}$ & Coleoptera & Philippines & KJ398610 & KJ398708 & KJ398801 & KJ398571 & \\
\hline Metarhizium majus & ARSEF 1946 & Coleoptera & Philippines & EU248919 & EU248947 & EU248867 & EU248839 & \\
\hline Metarhizium marquandii & CBS $182.27^{b}$ & soil & USA & EF468899 & EF468942 & EF468793 & KJ398548 & \\
\hline Metarhizium minus & ARSEF 1764 & Hemiptera & Solomon Isl. & KJ398609 & KJ398707 & KJ398800 & KJ398570 & HM055453 \\
\hline
\end{tabular}




\begin{tabular}{|c|c|c|c|c|c|c|c|c|}
\hline Metarhizium minus & ARSEF $2037^{b}$ & Hemiptera & Philippines & DQ522400 & DQ522454 & DQ522353 & KJ398576 & AF138271 \\
\hline Metarhizium novozealandicum & ARSEF 3056 & Coleoptera & New Zealand & KJ398621 & KJ398719 & KJ398810 & KJ398583 & \\
\hline Metarhizium novozealandicum & ARSEF 4661 & soil & Australia & KJ398622 & KJ398720 & KJ398811 & KJ398584 & \\
\hline Metarhizium novozealandicum & F530 & Platypus sp. & New Zealand & & & & & DQ385622 \\
\hline Metarhizium novozealandicum & FI-1125 & soil & Australia & & & & & AF139853 \\
\hline Metarhizium pemphigi & ARSEF 6569 & Hemiptera & UK & KJ398624 & KJ398722 & KJ398813 & KJ398586 & \\
\hline Metarhizium pemphigi & ARSEF 7491 & Hemiptera & UK & KJ398629 & KJ398728 & KJ398819 & KJ398591 & \\
\hline Metarhizium pemphigi & CABI 177416 & Hemiptera & UK & KJ398630 & KJ398729 & KJ398820 & KJ398592 & \\
\hline Metarhizium pemphigi & FI-72 & Homoptera & UK & & & & & AF139850 \\
\hline Metarhizium pemphigi & qc1401 & Melanotus cribricollis & China & & & & & КТ371489 \\
\hline Metarhizium pinghaense & ARSEF 4342 & Coleoptera & Solomon Isl. & EU248903 & EU248931 & EU248851 & EU248821 & \\
\hline Metarhizium pinghaense & ARSEF 7929 & Isoptera & Australia & EU248899 & EU248927 & EU248847 & EU248815 & \\
\hline Metarhizium pinghaense & CBS $257.90^{\mathrm{b}}$ & Coleoptera & China & EU248902 & EU248930 & EU248850 & EU248820 & \\
\hline Metarhizium rileyi & ARSEF 936 & Lepidoptera & Brazil & KJ398607 & KJ398705 & KJ398798 & KJ398566 & \\
\hline Metarhizium rileyi & ARSEF 1972 & Lepidoptera & Brazil & KJ398613 & KJ398711 & KJ398803 & KJ398574 & \\
\hline Metarhizium robertsii & ARSEF 4739 & soil & Australia & EU248900 & EU248928 & EU248848 & EU248817 & \\
\hline Metarhizium robertsii & ARSEF 7501 & Coleoptera & Australia & EU248901 & EU248929 & EU248849 & EU248818 & \\
\hline Metarhizium sp. & NHJ11597 & c & c & HQ165743 & HQ165643 & HQ165683 & & HQ165703/AY646375 \\
\hline Metarhizium sp. & NHJ11618 & c & c & HQ165744 & HQ165644 & HQ165684 & & HQ165704/AY646376 \\
\hline Metarhizium sp. & MY00896 & c & c & HQ165739 & HQ165638 & HQ165678 & & HQ165697 \\
\hline Metarhizium viride & ARSEF 2456 & Chamaeleo lateralis & c & KJ398619 & KJ398717 & KJ398808 & KJ398581 & \\
\hline Metarhizium viridulum & ARSEF 6927 & Hemiptera & Taiwan & KJ398626 & KJ398724 & KJ398815 & KJ398588 & \\
\hline Metarhizium yongmunense & EFCC 2131 & Lepidoptera & Korea & EF468876 & KJ398690 & EF468770 & KJ398542 & \\
\hline Pochonia chlamydosporia var. chlamydosporia & CBS $103.65^{b}$ & soil under Brassica napus & Germany & KJ398597 & KJ398693 & KJ398786 & KJ398554 & \\
\hline Pochonia chlamydosporia var. chlamydosporia & CBS $429.64^{b}$ & soil & Brazil & KJ398602 & KJ398698 & KJ398791 & KJ398559 & \\
\hline Pochonia chlamydosporia var. chlamydosporia & CBS $594.66^{b}$ & soil & Guinea & KJ398603 & KJ398699 & KJ398792 & KJ398560 & \\
\hline
\end{tabular}

a Abbreviations for collections: ARSEF, USDA-ARS Collection of Entomopathogenic Fungal Cultures, Ithaca, NY, USA; CABI, CAB International Bioscience, Egham, UK; CBS, Centraalbureau voor Schimmelcultures, Utrecht, the Netherlands; EFCC, Entomopathogenic Fungal Culture Collection, Chuncheon, Korea; F, AgResearch Insect Pathogen Culture Collection, Lincoln, New Zealand; FI, CSIRO Collection, Canberra, Australia; IMI, International Mycological Institute, CAB Bioscience, Egham, UK; IP, Institute of Tropical Pathology and Public Health, Federal University of Goiás, Goiânia, Goiás, Brazil; NBRC, Biological Resource Center, National Institute of Technology and Evaluation, Tokyo, Japan; UAMH Centre for Global Microfungal Biodiversity, Toronto, Canada.

b Denotes ex-type isolate.

c Collection source information not available. 


\section{Results}

\section{Observations on the field-collection and initial processing of material}

A brownish adult dead mycotized cockroach (13 $\mathrm{mm}$ length), was detected fixed to the underside of a leaf at a height of ca. $50 \mathrm{~cm}$ in the Bacupari Reserve (S $13^{\circ} 48^{\prime} 16.85^{\prime \prime}$ and W $47^{\circ} 25^{\prime} 38.43^{\prime \prime}$, WGS 84) on 4 February 2015. The surface of the cadaver was extensively covered by mycelium, and a large amount of light grey-green conidia forming columnar to plate-like masses, typical for the entomopathogenic genus Metarhizium (Figs 1-4) was observed. This cockroach and one other similarly infected individual collected at this site showed significant growth of a Metarhiziumlike fungus on its surface and were collected from the field. Both insects were returned to the field laboratory in the evening for microscopic determination of the identity of the fungus and to attempt to isolate cultures. The specimen reported on here proved to be sufficiently fresh to enable the isolation of the fungus. The second specimen was too old and in a somewhat degraded condition, and produced no subsequent fungal growth.

Both cockroach specimens were identified morphologically as belonging to the family Ectobiidae (Blattodea). Ectobiid cockroaches are wild non-synanthropic, mostly diurnal feeders on decaying organic material in forests and are common in Brazil and other South American countries (Costa Lima 1938; Lopes et al. 2014b; Beccaloni 2014).

\section{Pathogenicity against Periplaneta americana}

The first infected nymph died within $24 \mathrm{~h}$ after exposure to conidia. Cumulative mortality of nymphs increased markedly in the following days, and reached $96 \%( \pm 1.9 \%)$ after $10 \mathrm{~d}$ (Fig 2). All control nymphs had survived at this time. Mycelium and conidia, respectively, of the Metarhizium isolate developed on dead nymphs after 5 and $8 d$ of incubation of cadavers in a humid chamber. A total of $20 \pm 20 \%$ dead nymphs were found over the following $10 \mathrm{~d}$ with mycelium and conidia of the previously inoculated fungus.

\section{Taxonomy}

Metarhizium blattodeae Montalva, Humber, Collier \& Luz, sp. nov. (Figs. 1-4)

Mycobank MB 815131

Colonies on SDAY/4 initially colourless, becoming increasingly yellow below developing conidial hymenia. Conidiophores showing obtuse, candalabrum-like open branching, becoming intertwined in dense hymenia with closely crowded conidiogenous cells at apices of 1-5 branches per conidiophore. Conidiogenous cells ovoid to broadly ellipsoid, $7.1 \pm 0.3 \times 2.1 \pm 0.1$ (overall range: $5.8-8.4 \times 1.8-2.6 \mu \mathrm{m}$ ). Conidia cylindrical, $5.9 \pm 0.1 \times 2.3 \pm 0.0 \mu \mathrm{m}$ (overall range: 4.9-7.4 × 1.7-3 $\mu \mathrm{m}$ ), greyish-green in mass (plate 28-6-d; Kornerup \& Wanscher 1967), formed in long, laterally adherent chains forming columns or plates.

Holotype: UFG 49886, deposited in the Herbarium of the Federal University of Goiás, Goiânia, Brazil; a single infected cockroach, now detached from the subtending leaf.
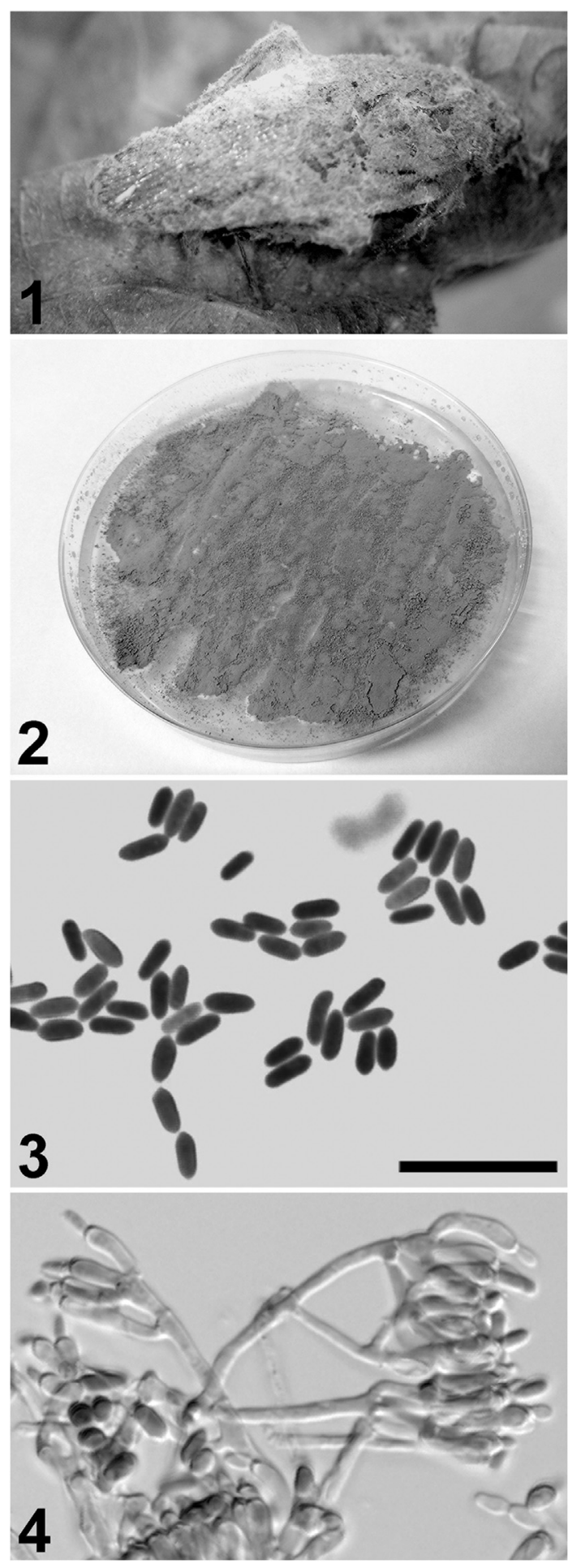

Figs 1 - 4 Metarhizium blattodeae. 1. Holotype specimen on leaf surface. 2. Culture of IP 414 on SDAY/4. 3. Conidia. 4. Conidiogenous cells. The micrographs of conidia and conidiogenous cells were prepared as photomontages combining several focal planes. Bar (Figs. 3 and 4) $=20 \mu \mathrm{m}$ ).

Ex-Type culture: ARSEF 12850 (=IP 414), USDA-ARS Collection of Entomopathogenic Fungal Cultures (Ithaca, New York), collected by Cristian Montalva, 4 February 2015.

Type host: An undetermined species of Dictyoptera: Blattodea: Ectobiidae. 


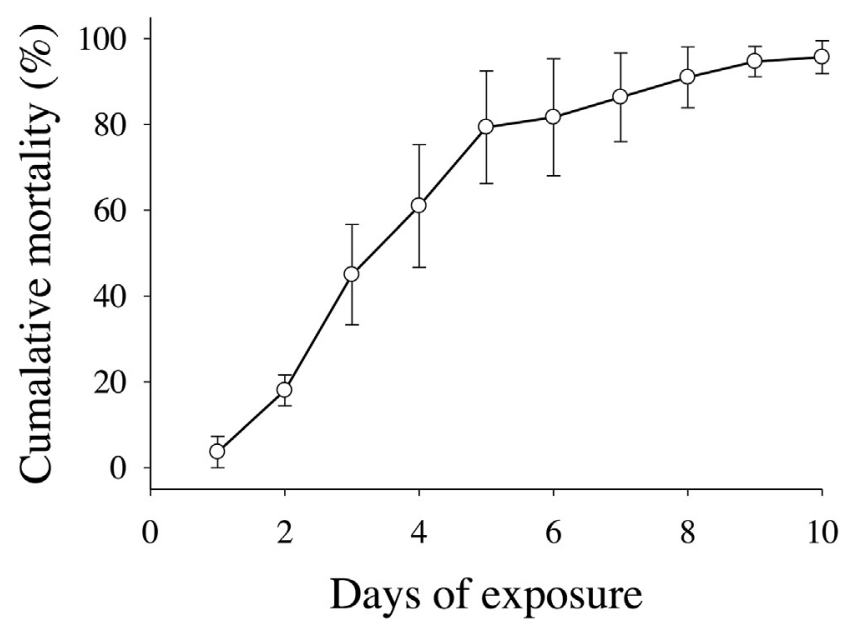

Fig 2 - Cumulative mortality of Periplaneta americana nymphs infected with Metarhizium blattodeae conidia under laboratory conditions. The scale bars represent the standard error of the means for three replicates.

Type locality: Bacupari Reserve, Cavalcante, Goiás, Brazil; S

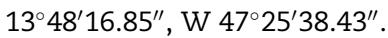

Etymology: The specific epithet refers to the name of the order of the host cockroach from which this species was recovered.

\section{Phylogenetic and other molecular placements of Metarhizium blattodeae in its genus}

The phylogenetic analysis of the combined partial BTUB, RPB1a, RPB2a and TEF gene dataset clearly place isolate IP 414 within the strongly supported clade comprising the Metarhizium flavoviride species complex (Fig 3). The short branch uniting the IP 414-Metarhizium minus-Metarhizium koreanumMetarhizium pemphigi clade with the remainder of the M. flavoviride species complex is unsupported (Fig 3), however, as is the short branch uniting Metarhizium frigidum and M. flavoviride, which agrees with the most recently published phylogenetic and nomenclatural treatment of Metarhizium (Kepler et al. 2014). IP 414 should therefore be considered as part of a basal polytomy in the M. flavoviride species complex, along with $M$. frigidum and $M$. flavoviride itself. With the exception of $M$. pemphigi, all the species comprising this complex are represented in the analysis by ex-type isolates (Kepler et al. 2014). The relationships revealed in the ITS analysis (Fig 4) agree with and support the multi-gene analysis, where the IP 414 isolate was distinct from both the M. minus-M. koreanum-M. pemphigi clade and from the unsupported M. frigidum-M. flavoviride clade.

IP 414 could not be identified by MS from within the previously established MSP database since the average log score value was only $0.97(0.87-1.16)$, lower than the cut-off value of 1.70 suggested by Lopes et al. (2014a) for this genus. The dendrogram of protein-based MALDI-TOF MS profiles (Fig 5) clearly distinguished IP 414 from any other identified Metarhizium species in the MSP. Strains of the same species (spectra matching with $\log$ scores $\geq 1.70$ ) show more than $90 \%$ protein profile similarity according to the software algorithm.

\section{Discussion}

The IP 414 isolate was immediately and unambiguously recognizable from its general appearance, conidial shape and aggregation of conidial chains in dense columns and plates as a species of Metarhizium (Tulloch 1976; Rombach et al. 1986). In the current systematics of hypocrealean entomopathogens, it is recognized that the species can be and often are defined only by their genomic characters, and that morphological characters can no longer be regarded as necessarily adequate to identify species within this extremely large and taxonomically complex group of fungi.

In addition to the now virtually mandatory use of key gene sequences to distinguish phylogenetically justified species of Metarhizium (Bischoff et al. 2009; Kepler et al. 2014), it was recently shown that a mass spectrometric method of examining and comparing Metarhizium species can be useful (Lopes et al. 2014a). MALDI-TOF (matrix-assisted laser desorption/ ionization-time of flight) mass spectrometry produced a protein profile for IP 414 unambiguously differentiating this fungus from all species of Metarhizium currently included in the MSP library. This protein-based analysis underscored the great variability within this genus and reinforced the multigenic sequence analysis supporting the description of this new species, even though the MALDI-TOF dendrogram is not congruent with the DNA-based phylogenetic trees (Figs 3 and 4) in every aspect. That differences between gene- and MS-based dendrogram topologies can occur was reported for both Alternaria (Brun et al. 2013) and Metarhizium (Lopes et al. 2014a). These differences may be due to metabolites produced by one species that resemble or are the same as those produced by other species.

BLAST searches of GenBank records, using the IP 414 Brazilian cockroach pathogen TEF, RPB1, RPB2 and ITS sequences, all returned strong matches to three unnamed Metarhizium sp. strains (MY00896, NHJ11597, and NHJ11618), for which no description of a new species seems to have been published. The GenBank records, submitted in 2010, do not indicate the geographical origin or host insect (if any) of these isolates. Duplicate ITS sequences from the NHJ11597 and NHJ11618 strains, submitted earlier to Genbank in 2004, are recorded as Metarhizium flavoviride. These three strains were included in our phylogenetic analyses, where they clustered closely together with IP 414 in both the ITS and combined four-locus trees. Although the MY00896, NHJ11597 and NHJ11618 strains were found to differ from IP 414 by between one to three base substitutions or indels in the ITS, TEF and RPB1a sequences and by zero to one base substitution in RPB2a (see Appendix A), they are most appropriately identified as Metarhizium blattodeae.

A diverse range of sylvatic cockroaches is now moving into increasingly large-scale production as pets or as alternative food sources for animals and humans (Anankware et al. 2015). Whether or not M. blattodeae is well adapted to cockroach hosts, this species and, potentially, other entomopathogenic fungi could represent a distinct threat to this new 


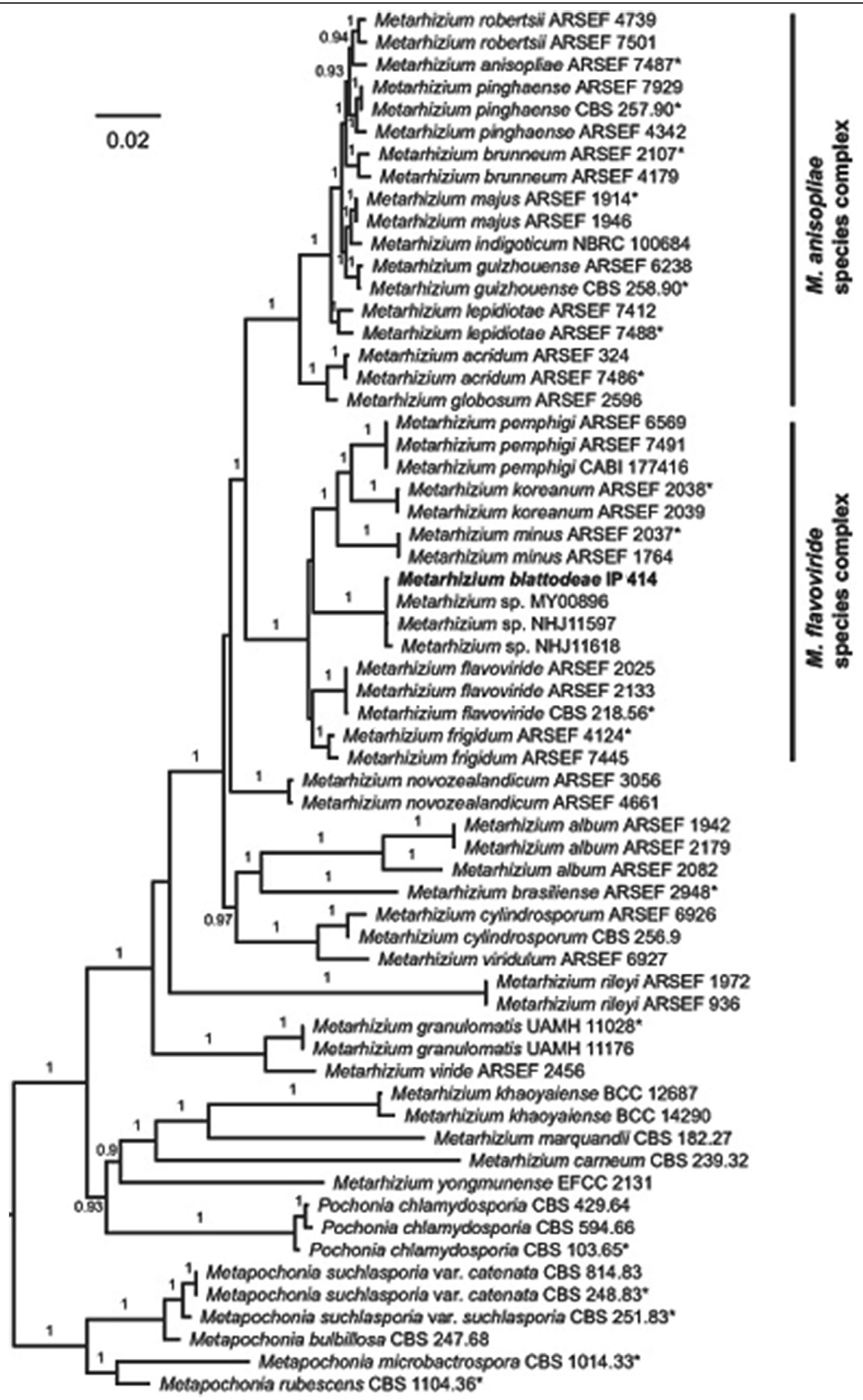

Fig 3 - Phylogenetic hypothesis based on Bayesian analysis of a concatenated dataset comprising partial BTUB, RPB1a, RPB2a and TEF gene sequences. Trees were rooted using Metapochonia spp. as outgroup, and posterior probabilities $>0.9$ are indicated. *ex-type isolate. The scale bar represents the number of expected substitutions per site. 


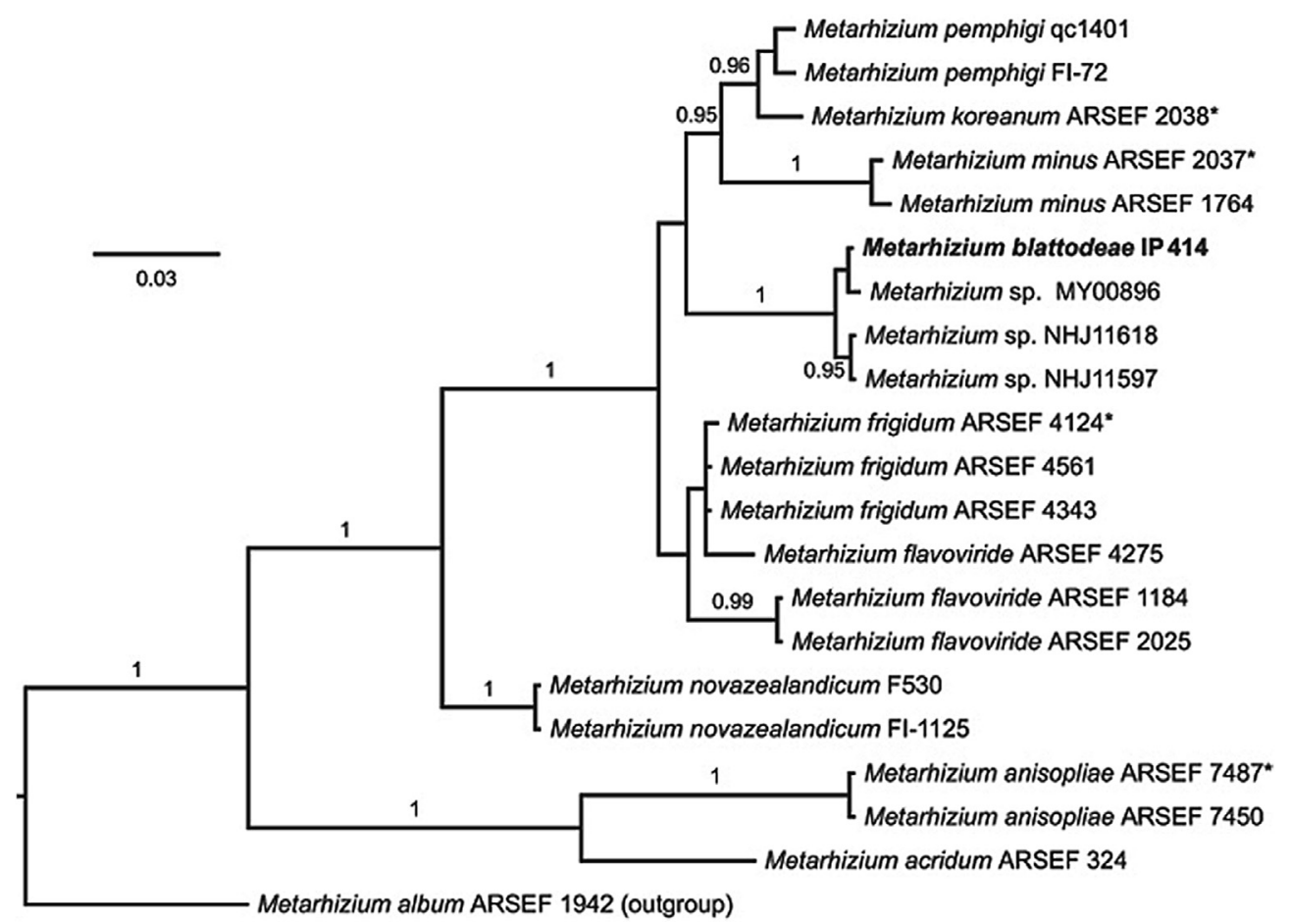

Fig 4 - Phylogenetic hypothesis based on Bayesian analysis of rRNA-ITS gene sequences. Trees were rooted using Metarhizium album as outgroup, and posterior probabilities $>0.9$ are indicated. ${ }^{*}$ ex-type isolate. The scale bar represents the number of expected substitutions per site.

alternative foods industry, and increased vigilance against fungal and other diseases of these insects would be prudent.

Naturally occurring populations of cockroaches in forests or fields are not regarded to be pests needing to be managed by the use of pesticides or other control strategies. It is significant, however, that M. blattodeae was shown here to be able to cause high mortality to nymphs of the serious domestic pest species, Periplaneta americana (American cockroach). No tests have yet been conducted to determine whether this new fungal species also shows activity against any other important cockroach

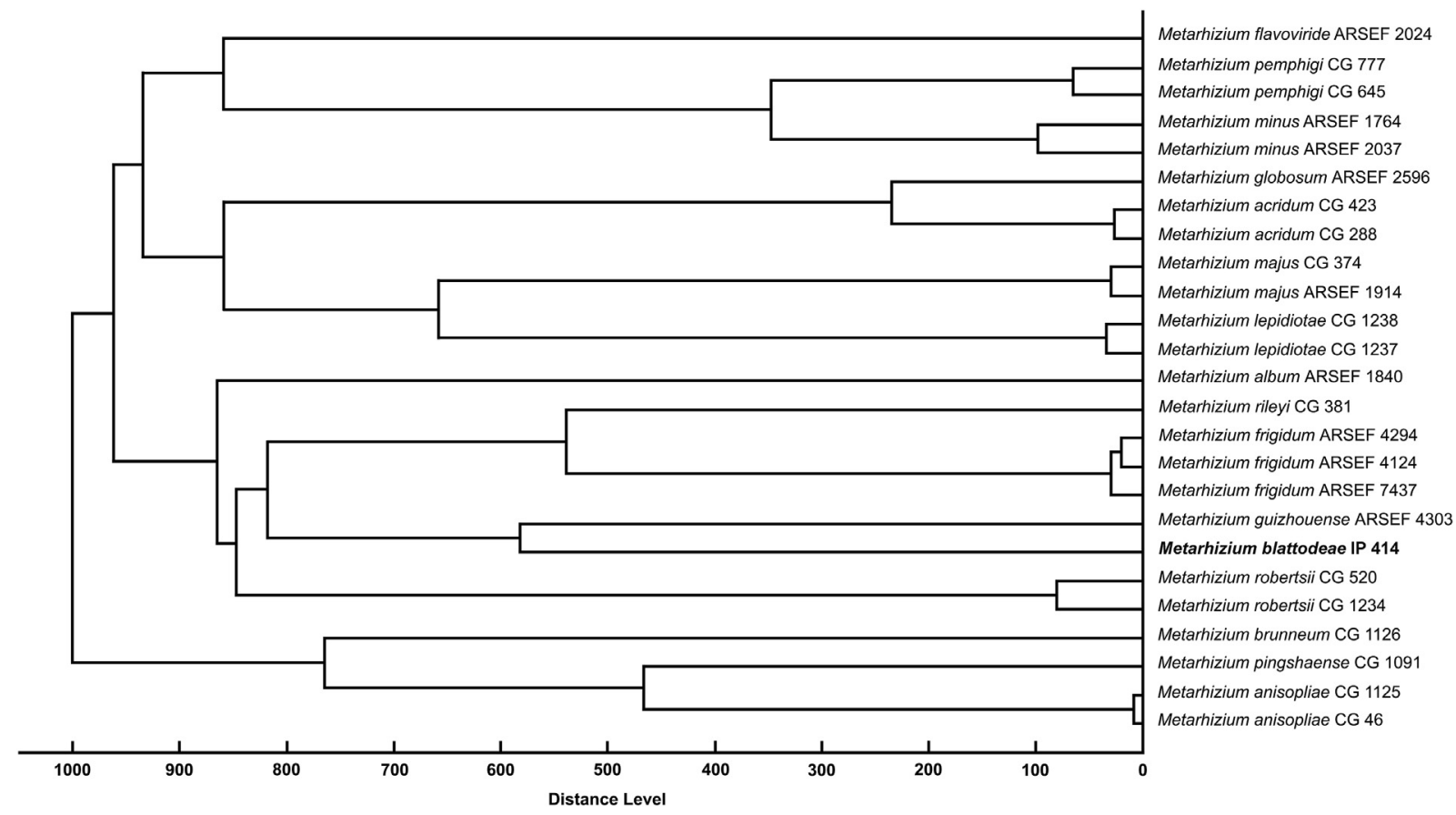

Fig 5 - Dendrogram showing cluster analysis of MALDI-TOF mass spectra. 
species. Despite being significantly pathogenic for P. americana, this new fungus did not sporulate well on those individuals that it had killed; the degree of sporulation on these American cockroach cadavers was notably less than is usually seen on insects that are highly susceptible to various Metarhizium species. If $\mathrm{M}$. blattodeae were to be developed for the applied biological control of domestic cockroach pests, its apparent reluctance to sporulate on those hosts might be seen as a significant benefit for the formulated product. The impaired ability of the fungus to establish itself at its application sites or to start any sort of outbreak in its host populations could result in increased product sales while also limiting any threats to non-target hosts.

\section{Acknowledgements}

The authors particularly thank Fabio Padula (Bacupari Reserve, Cavalcante, GO), who provided material assistance in the collection of the Brazilian isolate discussed here. Amanda Cardoso (IPTSP) and Daniela Aguiar Souza (Embrapa, Brasília) provided technical assistance. This study was supported by CAPES-CSF (Coordination of the Improvement of Higher Education-Science without Borders) project PVE 71/2013, 149988 and IFG-PROAPP 006/2014.

\section{Appendix A. Supplementary data}

Supplementary data related to this article can be found at http://dx.doi.org/10.1016/j.funbio.2016.03.004.

\section{R E F E R E N C E S}

Abedi A, Dayer MS, 2005. Evaluation of the effect of the fungus Metarhizium anisopliae, as a biological control agent, on German cockroaches Blattella germanica. Journal of Medical Science 8: 31-36.

Anankware PJ, Fening KO, Osekre E, Obeng-Ofori D, 2015. Insects as food and feed: a review. International Journal of Agricultural Research and Reviews 3: 143-151.

Appel AG, Archbold EF, Rust MK, 1987. Entomopathogenic fungal infection (Deuteromycotina: Hyphomycetes) affects water relations of the German cockroach, Blattella germanica (L.) (Dictyoptera: Blattellidae). Comparative Biochemistry and Physiology, Part A: Physiology 88: 491-493.

Archbold EF, Rust MK, Reierson DA, 1987. Diagnosis of a pathogenic fungus (Deuteromycotina: Hyphomycetes) of German cockroaches, Blattella germanica (Dictyoptera: Blattellidae). Journal of Medical Entomology 24: 269-272.

Beccaloni GW, 2014. Cockroach Species File Online Version 5.0/5.0. World Wide Web electronic publication (accessed 28.03.16). http://cockroach.speciesfile.org.

Bell WJ, Roth LM, Nalep CA, 2007. Cockroaches: ecology, behavior and natural history. The Johns Hopkins University Press, Baltimore.

Benjamin RK, Blackwell M, Chapela IH, Humber RA, Jones KG, Klepzig KD, Lichtwardt RW, Malloch D, Noda H, Roeper RA, Spatafora JW, Weir A, 2004. Insect- and other arthropodassociated fungi. In: Mueller GM, Bills GF, Foster MS (eds), Biodiversity of Fungi: Inventory and Monitoring Methods. Elsevier Academic Press, Amsterdam, pp. 395-433.

Bischoff J, Rehner SA, Humber RA, 2009. A multilocus phylogeny of the Metarhizium anisopliae lineage. Mycologia 101: 512-530.
Brun S, Madrid H, Van den Ende BG, Andersen B, MarinachPatrice C, Mazier D, de Hoog GS, 2013. Multilocus phylogeny and MALDI-TOF analysis of the plant pathogenic species Alternaria dauci and relatives. Fungal Biology 117: 32-40.

Costa Lima A, 1938. Insetos do Brasil, Vol. 1 Escola Nacional de Agronomia, Série Didática № 2, Rio de Janeiro.

Cummings NJ, 2009. Entomopathogenic fungi in New Zealand native forests: the genera Beauveria and Isaria PhD dissertation, University of Canterbury, Canterbury, New Zealand.

Faria MR, Wraight SP, 2007. Mycoinsecticides and mycoacaricides: a comprehensive list with worldwide coverage and international classification of formulation types. Biological Control 43: 237-256.

Gutierrez AC, Gołębiowski M, Pennisi M, Peterson G, García JJ, Manfrino RG, López Lastra CC, 2015. Cuticle fatty acid composition and differential susceptibility of three species of cockroaches to the entomopathogenic fungi Metarhizium anisopliae (Ascomycota, Hypocreales). Journal of Economic Entomology 108: 752-760.

Hubner-Campos RF, Leles RN, Rodrigues J, Luz C, 2013. Efficacy of entomopathogenic hypocrealean fungi against Periplaneta americana. Parasitology International 62: 517-521.

Huelsenbeck JP, Larget B, Alfaro ME, 2004. Bayesian phylogenetic model selection using reversible jump Markov chain Monte Carlo. Molecular Biology and Evolution 21: 1123-1133.

Humber RA, 2012a. Identification of entomopathogenic fungi. In: Lacey L (ed.), Manual of Techniques in Invertebrate Pathology. Academic Press (Elsevier Science), Amsterdam, pp. 153-189.

Humber RA, 2012b. Preservation of entomopathogenic fungal cultures. In: Lacey L (ed.), Manual of Techniques in Invertebrate Pathology. Academic Press (Elsevier Science), Amsterdam, pp. 319-330.

Hywel-Jones NL, 1995. Hymenostilbe venticosa sp. nov. a pathogen of cockroaches in Thailand. Mycological Research 99: 1201-1204.

Kaakeh W, Reid BL, Bennett GW, 1996. Horizontal transmission of the entomopathogenic fungus Metarhizium anisopliae (Imperfect fungi: Hyphomycetes) and hydramethylnon among German cockroaches (Dictyoptera: Blattellidae). Journal of Entomological Science 31: 378-390.

Kaakeh W, Reid BL, Bohnert TJ, Bennett GW, 1997. Toxicity of imidacloprid in the German cockroaches (Dictyoptera: Blattellidae) and the synergism between imidacloprid and Metarhizium anisopliae (Imperfect fungi: Hyphomycetes). Journal of Economic Entomology 90: 473-482.

Katoh K, Standley DM, 2013. MAFFT Multiple Sequence Alignment Software Version 7: improvements in performance and usability. Molecular Biology and Evolution 30: 772-780.

Kepler RM, Humber RA, Bischoff JF, Rehner SA, 2014. Clarification of generic and species boundaries for Metarhizium and related fungi through multigene phylogenetics. Mycologia 106: 811-829.

Kornerup A, Wanscher JH, 1967. Methuen Handbook of Colour, 2nd edn. Methuen and Co., Ltd., London.

Liu YJ, Whelen S, Hall BD, 1999. Phylogenetic relationships among ascomycetes: evidence from an RNA polymerase II subunit. Molecular Biology and Evolution 16: 1799-1808.

Lopes RB, Alves SB, 2011. Differential susceptibility of adults and nymphs of Blattella germanica (L.) (Blattodea: Blattellidae) to infection by Metarhizium anisopliae and assessment of delivery strategies. Neotropical Entomology 40: 368-374.

Lopes RB, Faria M, Souza DA, Bloch Jr C, Silva LP, Humber R, 2014a. MALDI-TOF mass spectrometry applied to identifying species of insect-pathogenic fungi from the Metarhizium anisopliae complex. Mycologia 106: 865-878.

Lopes SM, Oliveira EH, Tarli V, 2014b. Five new species of Ectobiidae (Blattodea) collected in the Reserva Ducke, Amazonas, Brazil. Biota Neotropica 14: e20130079.

Meier R, Kwong S, Vaidya GP, Ng PKL, 2006. DNA barcoding and taxonomy in Diptera: a tale of high intraspecific variability 
and low identification success. Systematic Biology 55: 715-728.

Mohan CHM, Lakshmi KA, Devi KU, 1999. Laboratory evaluation of the pathogenicity of three isolates of the entomopathogenic fungus Beauveria bassiana (Bals.) Vuillemin on the American cockroach (Periplaneta americana). Biocontrol Science and Technology 9: 29-33.

Quesada-Moraga E, Quirós RS, Garcia PV, Álvarez CS, 2004. Virulence, horizontal transmission, and sublethal reproductive effects of Metarhizium anisopliae (anamorphic fungi) on the German cockroach (Blattodea: Blattellidae). Journal of Invertebrate Pathology 87: 51-58.

Rehner SA, Buckley E, 2005. A Beauveria phylogeny inferred from nuclear ITS and EF1- $\alpha$ sequences: evidence for cryptic diversification and links to Cordyceps teleomorphs. Mycologia 97: 84-98.

Rombach MC, Humber RA, Roberts DW, 1986. Metarhizium flavoviride var. minus var. nov., a pathogen of plant and leaf hoppers on rice in the Philippines and Solomon Islands. Mycotaxon 27: 87-92.

Ronquist F, Teslenko M, Van Der Mark P, Ayres DL, Darling A, Höhna S, Larget B, Liu L, Suchard MA, Huelsenbeck JP, 2012. MrBayes 3.2: efficient Bayesian phylogenetic inference and modelchoice across a large model space. Systematic Biology 61: 539-542.
Roth LM, Willis ER, 1960. The biotic associations of cockroaches. Smithsonian Miscellaneous Publications 141: 1-470.

Sosa-Gómez DR, López Lastra CC, Humber RA, 2010. An overview of arthropod-associated fungi from Argentina and Brazil. Mycopathologia 170: 61-76.

Sousa NA, Lobo LS, Rodrigues J, Luz C, 2013. New insights on the effectiveness of Metarhizium anisopliae formulation and application against Aedes aegypti eggs. Letters of Applied Microbiology 57: 193-199.

Stiller JW, Hall BD, 1997. The origin of red algae: Implications for plastid evolution. Proceedings of the National Academy of Sciences 94: $4520-4525$.

Tulloch M, 1976. The genus Metarhizium. Transactions of the British Mycological Society 66: 407-411.

White TJ, Bruns TD, Lee SB, Taylor JW, 1990. Amplification and direct sequencing of fungal ribosomal RNA genes for phylogenetics. In: Innis MA, Gelfand DH, Sninsky JJ, White TJ (eds), PCR Protocols: a guide to methods and applications. Academic Press, San Diego, pp. 315-322.

Zurek L, Watson DW, Schal C, 2002. Synergism between Metarhizium anisopliae (Deuteromycota: Hyphomycetes) and boric acid against the German cockroach (Dictyoptera: Blattellidae). Biological Control 23: 296-302. 